J Arid Land 7(5): 567-578

doi: $10.1007 / \mathrm{s} 40333-015-0127-8$

jal.xjegi.com; www.springer.com/40333

\title{
Identification of sand and dust storm source areas
}

\section{in Iran}

\author{
CAO Hui ${ }^{1,2,3^{*}}$, LIU Jian ${ }^{2}$, WANG Guizhou ${ }^{4}$, YANG Guang ${ }^{3,4}$, LUO Lei $\mathrm{i}^{3,4}$ \\ ${ }^{1}$ Key Laboratory of Ecosystem Network Observation and Modeling, Institute of Geographic Sciences and Natural Resources \\ Research, Chinese Academy of Sciences, Beijing 100101, China; \\ ${ }^{2}$ International Ecosystem Management Partnership, United Nations Environment Programme, Beijing 100101, China; \\ ${ }^{3}$ University of Chinese Academy of Sciences, Beijing 100049, China; \\ ${ }^{4}$ Institute of Remote Sensing and Digital Earth, Chinese Academy of Sciences, Beijing 100094, China
}

\begin{abstract}
Sand and dust storms (SDS) are common phenomena in arid and semi-arid areas. In recent years, SDS frequencies and intensities have increased significantly in Iran. A research on SDS sources is important for understanding the mechanisms of dust generation and assessing its socio-economic and environmental impacts. In this paper, we developed a new approach to identify SDS source areas in Iran using a combination of nine related datasets, namely drought events, temperature, precipitation, location of sandy soils, SDS frequency, human-induced soil degradation (HISD), human influence index (HII), rain use efficiency (RUE) and net primary productivity (NPP) loss. To identify SDS source areas, we firstly normalized these datasets under uniform criteria including layer reprojection using Lambert conformal conic projection, data conversion from shapefile to raster, Min-Max Normalization with data range from 0 to 1 , and data interpolation by Kriging and images resampling (resolution of $1 \mathrm{~km}$ ). After that, a score map for the possibility of SDS sources was generated through overlaying multiple datasets under average weight allocation criterion, in which each item obtained weight equally. In the score map, the higher the score, the more possible a specific area could be regarded as SDS source area. Exceptions mostly came from large cities, like Tehran and Isfahan. As a result, final SDS source areas were mapped out, and Al-Howizeh/Al-Azim marshes and Sistan Basin were identified as main SDS source areas in Iran. The SDS source area in Al-Howizeh/Al-Azim marshes still keeps expanding. In addition, Al-Howizeh/Al-Azim marshes are now suffering rapid land degradation due to natural and human-induced factors and might totally vanish in the near future. Sistan Basin also demonstrates the impacts of soil degradation and wind erosion. With appropriate intensity, duration, wind speed and altitude of the dust storms, sand particles uplifting from this area might have developed into extreme dust storms, especially during the summer.
\end{abstract}

Keyw ords: sand and dust storm; weight allocation criterion; Kriging interpolation; score map; Al-Howizeh/Al-Azim marshes; Sistan Basin

Citation: CAO Hui, LIU Jian, WANG Guizhou, YANG Guang, LUO Lei. 2015. Identification of sand and dust storm source areas in Iran. Journal of Arid Land, 7(5): 567-578. doi: 10.1007/s40333-015-0127-8

Sand and dust storms (SDS) are common and catastrophic phenomena in arid and semi-arid areas. These phenomena can damage infrastructures, telecommunications and crops, affect transportation through reduced visibility, and cause tremendous economic losses. Carrying diversified allergens, dust storms also significantly threaten human health (Goudie, 2009; Higashi et al., 2014; Powell et al., 2015). In a general perspective, West Asia, including Arabian Peninsula,
Syria, Iraq and Iran, has been recognized as one of the most important primary sources of dust (Prospero et al., 2002; Boloorani et al., 2013; WMO and UNEP, 2013). The growing concern amongst countries in this region on SDS has led to numerous international meetings, cooperation and joint research to tackle sand and dust storms.

While there are many studies focusing on the atmospheric transport of dust particles and their paths,

"Corresponding author: CAO Hui (E-mail: hui.cao@unep-iemp.org)

Received 2014-11-07; revised 2015-01-16; accepted 2015-02-15

C Xinjiang Institute of Ecology and Geography, Chinese Academy of Sciences, Science Press and Springer-Verlag Berlin Heidelberg 2015 
less effort has been made in the identification of SDS source areas. This identification will enable us to look into the factors generating SDS more effectively (Esmaili et al., 2006a), and will improve our understanding of SDS mechanism and the effects of climate change and human activities on SDS occurrences. Despite the presence of abundant fine dust particles, SDS source regions exhibit spatial and temporal heterogeneities in dust emission characteristics, which makes the identification of SDS source areas a more complicated issue (Bullard et al., 2011; Bryant, 2013). The primary method to identify SDS source areas depends on ground-based point measurements that limit the ability to study events to large spatial scales (Esmaili et al., 2006b). With the development of satellite technology and computer science, remote sensing methods and meteorological simulation models have gradually played an important role in such large-scale studies. Using Total Ozone Mapping Spectrometer (TOMS) sensor on Nimbus 7 satellite, the global distribution of major atmospheric dust sources was identified (Prospero et al., 2002). For its unique characteristics in the analysis of dust particles, thermal infrared data (TIR) was also applied in the research of SDS sources (Furman, 2003; Mohammad, 2012). Other than the remote sensing methods, many meteorological models, especially HYSPLIT model (Hybrid Single-Particle Lagrangian Integrated Trajectory) (Draxler and Hess, 1997), have been developed for the simulation of sand and dust storms (Wang et al., 2011; Ashrafi et al., 2014). In addition, other models, such as CARMA-dust model (Barnum et al., 2004) and GOCART model (Ginoux et al., 2001), are still being applied in SDS studies. In recent years, synthetic researches combining remote sensing, meteorological models and GIS tools have become more and more popular (Esmaili et al., 2006b; Gerivani et al., 2011; Hamidi et al., 2013; Zoljoodi et al., 2013; Cao et al., 2014).

Iran is exposed to various environmental and social factors that contribute to desertification acceleration and land degradation. More than half of the Iranian provinces are suffering from critical wind erosion (Amiraslani and Dragovich, 2011; Keramat et al., 2011). In recent years, dust storm frequencies and intensities have increased significantly in Iran. Sand and dust storms have brought huge impacts on the economy and environment of Iran and the daily life of the Iranians. At least 5 million people have been directly influenced by sand and dust storms, and many more have been indirectly affected by transferring sand particles into their living environments (Morabbi, 2011). Under this background, a series of national actions authorized to Iran Environment Protection Organization (EPO) have been initiated to combat sand and dust storms, including the installation of monitoring stations for dust analysis, the enhancement of public awareness and public preparedness, and the development of SDS measurement systems using advanced technologies (Pegah Amiirdiivanii, 2012). Dust activities are extremely sensitive to environmental and socio-economic parameters, and previous researches have provided plenty of natural and human factors indicating the occurrence of sand and dust storms. By weighing a series of geographic layers highly associated with sand and dust storms, this study aims to identify and monitor SDS source areas in Iran.

\section{Study area}

Iran, with area of about $1,648,000 \mathrm{~km}^{2}$, lies approximately between $25^{\circ} 03^{\prime} \mathrm{N}$ and $39^{\circ} 47^{\prime} \mathrm{N}$ in latitude and between $44^{\circ} 05^{\prime} \mathrm{E}$ and $63^{\circ} 18^{\prime} \mathrm{E}$ in longitude. The climate is mainly arid and semi-arid, except in the northern coastal areas and western parts. The area coverage of different types of climate in Iran is $35.5 \%$ hyper-arid, $29.2 \%$ arid, $20.1 \%$ semi-arid, 5.0\% Mediterranean and $10.0 \%$ wet (Saboohi et al., 2012). The average annual precipitation in Iran is about $251 \mathrm{~mm}$, which is less than $1 / 3$ of the average of the world ( 831 $\mathrm{mm})$. The received precipitation extremely varies spatially and temporally and more than $70 \%$ of the annual precipitation is lost through evapotranspiration (Kousari et al., 2013). In addition, with recent multi-year drought and intensive atmospheric systems affecting West Asia, Iran has become a country vulnerable to climate change related phenomena, especially sand and dust storms.

\section{Materials and methods}

Multi-datasets of SDS source indicators were collected for Iran (Table 1), taking into account their re- 
lationships with sand and dust storms. These indicators include: Drought events, temperature, precipitation, location of sandy soils, SDS frequency, human-induced soil degradation (HISD), human influence index (HII), rain use efficiency (RUE) and net primary productivity (NPP) loss. We then normalized these datasets under uniform criteria comprising layer reprojection using Lambert conformal conic projection, data conversion from shapefile to raster, Min-Max Normalization with data range from 0 to 1 , data interpolation by Kriging and images resampling (resolution of $1 \mathrm{~km}$ ). After a series of data processing, a weight was allocated to each dataset using our weight allocation criterion. Thus, we could develop a synthetic potential map for SDS sources by accumulating the weighted datasets, and final SDS source clusters were generated consequently.

\subsection{SDS source indicators}

Nine datasets were collected in this paper, including natural and human-induced ones (Table 1). Drought events, referring to the condition of an insufficient supply of water necessary to meet the demand, have a remarkable potential to increase dust events especially in the external SDS source areas (Zoljoodi et al., 2013). With inadequate rainfall and vast desert areas under dry climates, temperature and precipitation are considered as two important climatic factors causing the formation of sand and dust storms (Keramat et al., 2011). Most of the SDS source regions are deserts, drying alluvial basins, large basins of internal drainage, areas of increased drought/ groundwater withdrawal, etc (Goudie, 2009; Muhs, 2013). In this perspective, location of sandy soils in certain underground levels could provide us with the degree of desertification and serve as potential source regions. We could not conclude a high frequency area of SDS as a source area, however, it is extremely likely to be if this area is identified as deserts, alluvial fans, river bed sediments or marsh sediments, etc (Gerivani et al., 2011). Human-induced Soil Degradation database was produced by GLASOD (ISRIC, 1990), using uniform guidelines and international cooperation of a large number of soil scientists. The soil degradation in the Human-induced Soil Degradation Map was catego- rized into four main types: water erosion, wind erosion, chemical deterioration and physical deterioration (Oldeman et al., 1990). The degree of soil degradation was estimated in relation to changes in agricultural suitability, declined productivity and, in some cases, reduced biotic functions. HII dataset, which provides anthropogenic impacts on the environment in geographic projection, was created from nine global data layers comprising of human population pressure, human land use, infrastructures and human access. Where rainfall is the main limiting factor on biomass productivity, RUE, calculated as the ratio of annual NDVI and station-observed annual rainfall, is a good indicator of land degradation and reluctant phenomena (Snyman, 1998; Illius and O'connor, 1999). NPP variation reflects land conditions and could be used as an indicator for SDS source areas.

\subsection{Data normalization}

Among the nine datasets, NPP Loss was already girdded at a $1-\mathrm{km}$ resolution and needs only the process of reprojection. Location of sandy soils was firstly represented by accumulating mean sand contents in different depths, and then reprojected using Lambert conformal conic projection. The original form of temperature, precipitation, HII and RUE was gridded data with latitude-longitude coordinates. These datasets were processed with resampling after reprojection. Drought events was represented as shapefile with polygon indicating the extent of each specific drought event. Before resampling and reprojection, we converted this dataset to a new layer counting occurrence of drought by overlapping the polygons. Human-induced Soil Degradation map exhibited the degree of soil degradation with four levels: light, moderate, strong and extreme. The processing of this shapefile dataset also followed three procedures including format conversion, reprojection and resampling.

SDS frequency was derived from meteorological data which included indicators of visibility and humidity. According to the definition by the World Meteorological Organization, dust storms are resultant of weather turbulences which introduce a high dust mass into the atmosphere, and consequently decrease the horizontal visibility to less than 1,000 m (Goudie and 
Table 1 Datasets for SDS source indicators

\begin{tabular}{|c|c|c|c|c|}
\hline Dataset & Source & Description & Type & Resolution/scale \\
\hline Drought events & $\begin{array}{l}\text { PreventionWeb (UNEP and } \\
\text { GRID-Europe, 2014) }\end{array}$ & $\begin{array}{l}\text { This dataset includes an estimate of global } \\
\text { drought annual repartition based on standard- } \\
\text { ized precipitation index }\end{array}$ & Shapefile & $1: 10,000,000$ \\
\hline Temperature & $\begin{array}{l}\text { WorldClim } \\
\text { (http://www.worldclim.org) }\end{array}$ & Mean temperature of the warmest quarter & Raster & 30 -second \\
\hline Precipitation & $\begin{array}{l}\text { WorldClim } \\
\text { (http://www.worldclim.org) }\end{array}$ & Precipitation of the driest quarter & Raster & 30 -second \\
\hline Location of sandy soils & SoilGrids (ISRIC, 2013) & $\begin{array}{l}\text { This dataset is a collection of updatable sand } \\
\text { content at the resolution of } 1 \mathrm{~km} \text { produced using } \\
\text { state-of-the-art model-based statistical methods }\end{array}$ & Raster & $1 \mathrm{~km}$ \\
\hline SDS frequency & $\begin{array}{l}\text { NOAA Climate.gov (NOAA, } \\
\text { 2013) }\end{array}$ & $\begin{array}{l}\text { SDS frequency is indicated by visibility and } \\
\text { humidity derived from meteorological station } \\
\text { data }\end{array}$ & $\begin{array}{l}\text { Meteorological } \\
\text { station data }\end{array}$ & - \\
\hline $\begin{array}{l}\text { Human-induced soil degra- } \\
\text { dation (HISD) }\end{array}$ & ISRIC (ISRIC, 1990) & $\begin{array}{l}\text { Soil degradation types include wind erosion, } \\
\text { water erosion, chemical deterioration and } \\
\text { physical deterioration }\end{array}$ & Shapefile & $1: 10,000,000$ \\
\hline $\begin{array}{l}\text { Human influence index } \\
\text { (HII) }\end{array}$ & GeoNetwork (WCS, 2005) & $\begin{array}{l}\text { This dataset derives from nine data layers in- } \\
\text { cluding human population pressure (population } \\
\text { density), human land use and infrastructures } \\
\text { (built-up areas, nighttime lights and land } \\
\text { use/land cover), and human access (coastlines, } \\
\text { roads, railroads and navigable rivers) }\end{array}$ & Raster & 30 -second \\
\hline Rain use efficiency (RUE) & GeoNetwork (FAO, 2008a) & $\begin{array}{l}\text { Ratio of annual NDVI and station-observed } \\
\text { annual rainfall }\end{array}$ & Raster & 0.0727 degree \\
\hline NPP loss & GeoNetwork (FAO, 2008b) & $\begin{array}{l}\text { A pixel-based estimate of the NPP loss is pre- } \\
\text { sented by comparing the average over the period } \\
1981-2003\end{array}$ & Raster & $1 \mathrm{~km}$ \\
\hline
\end{tabular}

Middleton, 2006). In this paper, we regard a meteorological phenomenon as a dust storm if the visibility was less than $1,000 \mathrm{~m}$. Furthermore, a threshold of humidity $(80 \%)$ was also set to distinguish from other weather phenomena like rain, mist or haze. After that, a map of SDS frequency (Fig. 1a) was generated based on meteorological data. The gridded SDS frequency map (Fig. 1b) was made compatible with all the other datasets by utilizing Kriging interpolation.

Although the datasets above are normalized, the values for each dataset are dimensionally diversified. For example, drought events and SDS frequency are represented by times, while temperature is represented by degree Celsius and precipitation is shown in millimeter. In order to make it possible for overlay analysis, we applied Min-Max Normalization (Eq. 1) to all these nine datasets.

$$
\mathrm{X}^{*}=\frac{\mathrm{X}-\mathrm{Min}}{\mathrm{Max}-\mathrm{Min}} .
$$

Where $\mathrm{X}^{*}$ represents the normalized value and $\mathrm{X}$ represents the original value; Max and Min are maxi- mum and minimum values in the sample data, respectively. Min-Max Normalization is a common linear transformation of the original data, with the result data ranging from 0 to 1 .

\subsection{Weight allocation criterion}

In this paper, it's difficult to judge which database is more important since these databases were collected with different themes (drought, SDS frequency, NPP, climate, etc). Thus, we developed an average weight allocation approach (Fig. 2), whose criterion followed the top-to-down concept with a basic rule: in a specific weight allocation, each item obtains weight equally. For example, the total weight was divided as drivers forming SDS source areas and related phenomena, thus both the drivers and related phenomena shared half of the total weight. Among these indicators, most of them had positive correlations with the distribution of SDS source areas except precipitation and RUE. For the convenience of overlay analysis, the final fractional weights were transformed into integer by multiplying their lowest common denominator. 

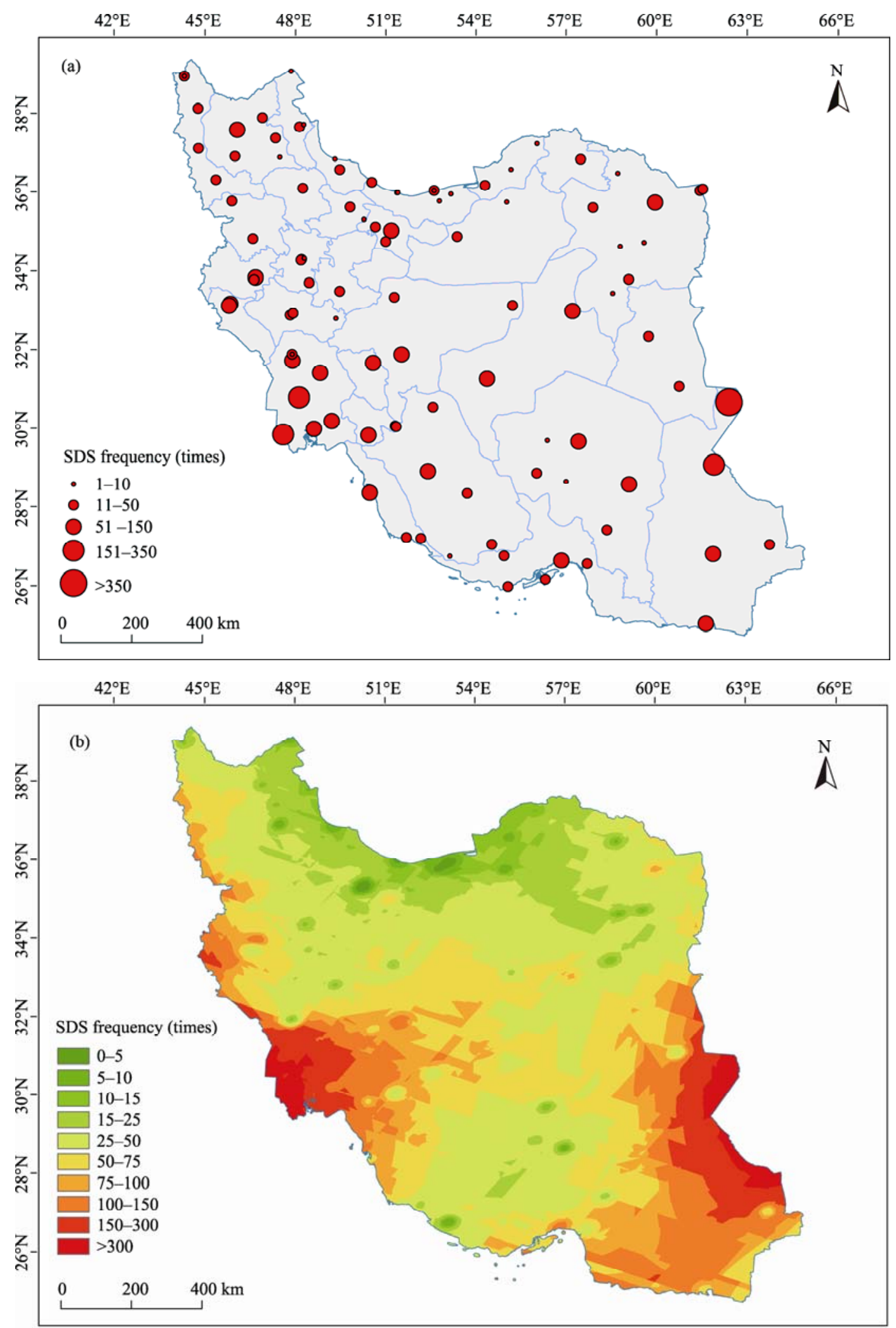

Fig. 1 Sand and dust storms (SDS) frequency map in Iran from 2000-2013. (a) Meteorological data-based SDS frequency map; (b) Gridded SDS frequency map interpolated by Kriging 


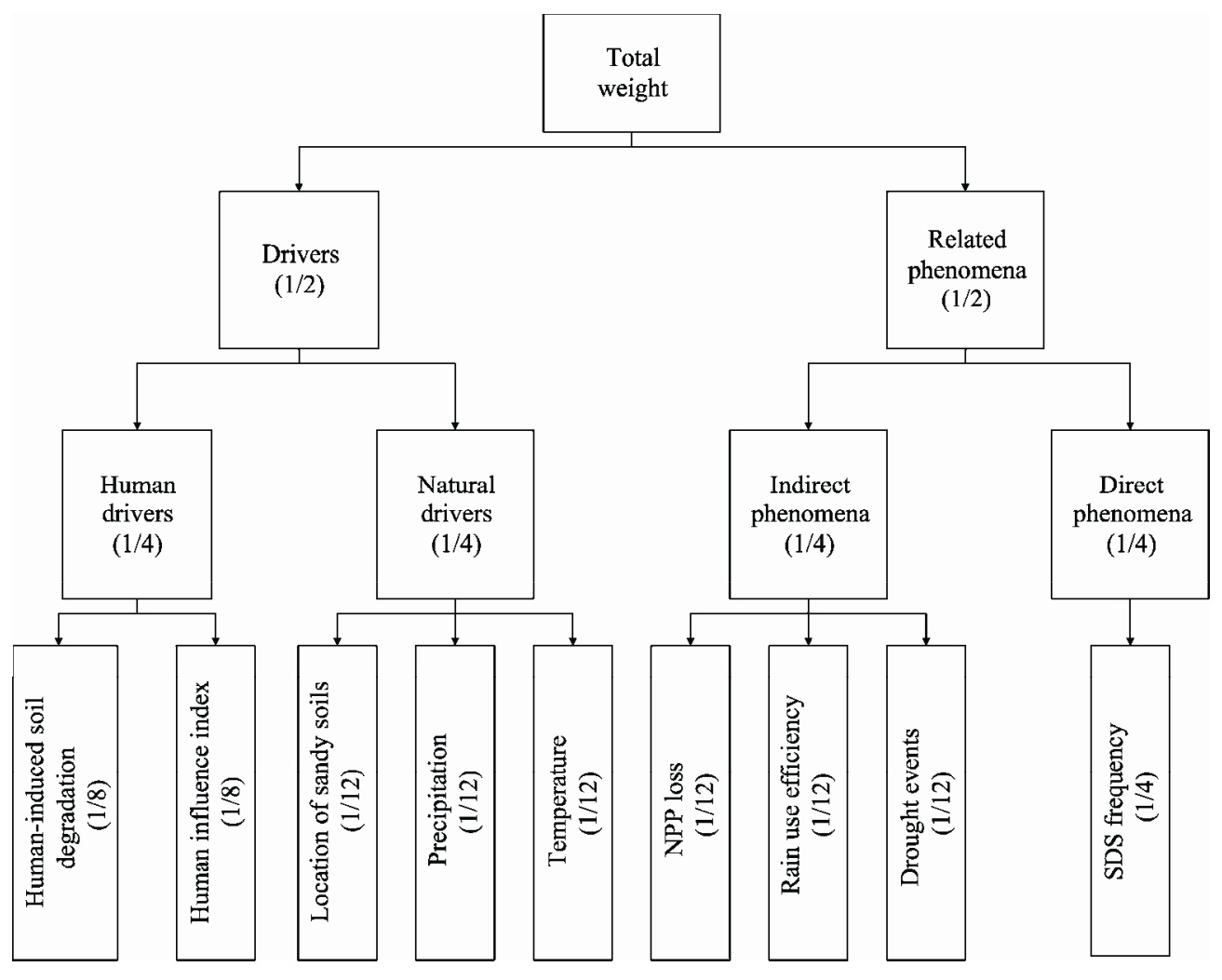

Fig. 2 Weight allocation criterion for SDS source indicators

The average weight allocation approach could regulate the contribution of SDS source indicators in case that the databases are insufficient. If there are enough databases under a specific sub-item, such as Human Drivers, each database will be allocated with a smaller weight and the influence of Human Drivers will be exhibited with more details. Otherwise, each database will get a larger weight so that the sub-item could remain its contribution to the final result. With specific hierarchy, this criterion is also convenient in database management when some databases need to be updated or supplemented in our future work.

\subsection{Remote sensing images}

To give a better view of the SDS source characteristics, we collected the newly released Landsat 8 images in 2013. Landsat 8 , as a significant improvement of Landsat series satellites, consists of two sensors: the Operational Land Imager (OLI) and the Thermal Infrared Sensor (TIRS). As the latest Landsat series, Landsat 8 not only receives stronger signals and improves signal-to-noise performance, but also adds new bands such as coastal and aerosol band (Band 1: ul- tra-blue), cirrus cloud band (Band 9), and adjusts the wavelength of each band which could avoid the atmospheric absorption feature (Li et al., 2013). In this paper, we used the band composite of 6 (short infrared), 5 (near infrared) and 4 (red) to exhibit the characteristics of SDS source areas.

\section{Results and discussion}

\subsection{Score map for the possibility of SDS sources}

After overlaying each dataset with specific weight, we generated a score map for the possibility of SDS sources in Iran (Fig. 3). In the score map, there are 4 suspected SDS source areas showing the highest scores: Al-Howizeh/Al-Azim marshes in Khuzestan province, the northeast part of Sistan and Baluchistan province, Tehran and Isfahan. Among the nine datasets above, drought events remains as a frequent disaster in Tehran, Isfahan and a few parts of Al-Howizeh/Al-Azim marshes. Temperature (mean temperature of the warmest quarter) contributes most to Al-Howizeh/Al-Azim marshes, and much more to the northeast part of Sistan and Baluchistan province, 


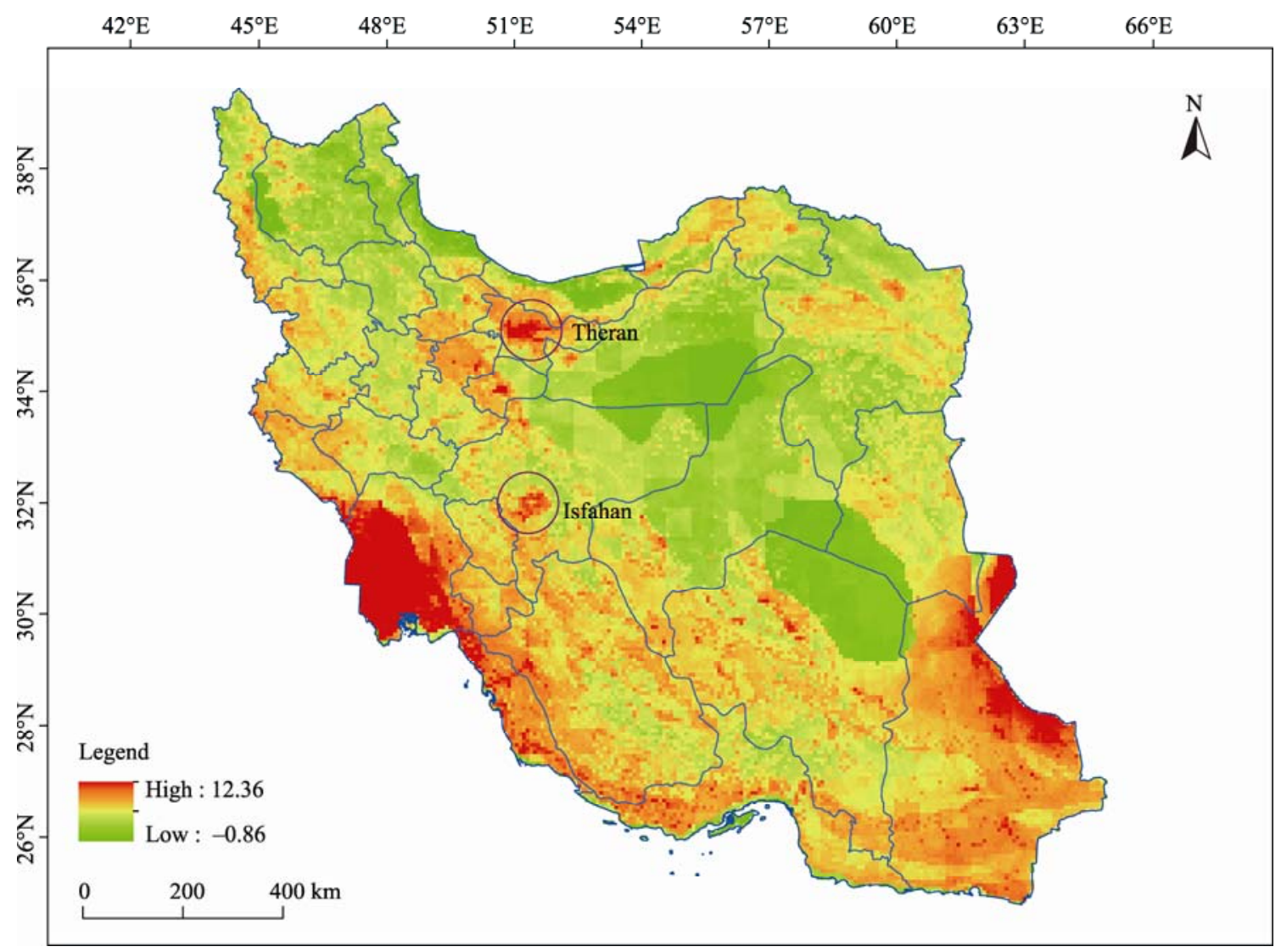

Fig. 3 Score map for the possibility of SDS sources in Iran

especially Sistan Basin. Tehran and Isfahan get lower values in this dataset. As for precipitation (precipitation of the driest quarter), all these four areas have low values. Al-Howizeh/Al-Azim marshes get the highest value in location of sandy soils, while the values for Tehran and Isfahan are medium. As Fig. 1 shows, Al-Howizeh/Al-Azim marshes in Khuzestan province and the northeast part of Sistan and Baluchistan province suffer the most frequent times of sand and dust storms (more than 200 times, with some areas even exceeding 400 times). Although Tehran and Isfahan exhibit lower values, they still account for approximate 70 times and 120 times, correspondingly. In the HISD dataset, only Al-Howizeh/Al-Azim marshes suffer extreme soil degradation. RUE keeps high values in Tehran and Isfahan, while exhibits low values or none value in Al-Howizeh/Al-Azim marshes in Khuzestan province and the northeast part of Sistan and Baluchistan province. Higher values mean that Tehran and Isfahan might not develop into SDS source areas. There are no significant variations of
NPP Loss in all these four suspected areas, except at the Iran-Iraq border of Al-Howizeh/Al-Azim marshes. Besides these highest scored areas, the coastal region of Persian Gulf also presents a higher score.

The other trend we can figure out from this score map is that the scores increase from north to west and south at the national level. Generally, Caspian Sea and central Iran present the lowest values under 3.5, while northeast and southeast show relative high scores ranging from 3 to 6 approximately. As for southern Iran, the average score could reach more than 6 .

Normally, the higher the score, the more possible a specific area can be regarded as an SDS source area. However, this rule cannot be applied everywhere in Iran. Among the highest score areas, larger cities, like Tehran and Isfahan (cities within the circles in Fig. 3) always suffer from greater HII, and NPP loss would increase rapidly under dense anthropogenic activities. With contributions from related phenomena (drought or SDS frequency), few large cities might obtain a higher score in the overlay analysis. Actually, Tehran, 
the capital and largest city in Iran, has been identified as one of the most frequent urban receptors of dust storms, according to previous literatures (Givehchi et al., 2013; Mohammadi et al., 2014). Similarly, the area located at the south of Sistan Basin shows no evidence as an SDS source area on Landsat 8 images and Google Earth, although it presents high scores (ranging from 8 to 10 approximately) due to drought weather and frequent dust storms originating from Sistan Basin. The coastal region of Persian Gulf with higher scores also has potential as SDS source areas to a certain extent. Actually, previous study indicates that few parts of this coastal region have developed to be SDS source areas (Cao et al., 2014).

The national trend in the score map for the possibility of SDS sources might be driven by complicated situations. Except for indigenous source areas, most sand and dust storms that happened in Iran came from eastern Syria, Iraq and Arabian Peninsula (Zoljoodi et al., 2013). Under the influence of one of the most important trajectories of the summer "shamal", or "wind of 120 days" (Wilderson, 1991), dust particles originating from Syria and Iraq are always enhanced in the west of Iran (Morabbi, 2011; AZIZI et al., 2012), especially at the Iraq-Iran border (Rahimi et al., 2014). Large quantities of deposited sand will accelerate desertification and consequently increase the possibility for this area to become an SDS source. As for the coastal areas of southern Iran, pre-frontal dust storms blowing from southern Arabian Peninsula and passing over Persian Gulf play a leading role in winter (Dadizadeh et al., 2013; Hamidi et al., 2013). Sand and dust storms in southeastern Iran mainly occurred in Sistan Basin (Esmaili et al., 2006b; Rashki et al., 2013a), which is also one of the most active SDS source areas in West Asia. Moreover, from both collected dataset and existing studies (Modarres and da Silva, 2007; Gerivani et al., 2011), the annual precipitation in Iran shows a decreasing trend from northwest to southeast. As previously mentioned, precipitation has a negative correlation with the distribution of SDS source areas. Frequent sand and dust storms in the west and south of Iran, coupled with relatively dry weather and low precipitation, finally result in the national distribution of SDS source scores in the map.

\subsection{Distribution of SDS source areas in Iran}

With analysis of the score map above, the SDS source areas in Iran were identified (Fig. 4). There are two prominent SDS source clusters in Iran: Al-Howizeh/ Al-Azim marshes and Sistan Basin. The Iranian part of Al-Howizeh/Al-Azim marshes is mainly located in Khuzestan province. Sitting on the trajectory of SDS blowing from eastern Syria and Iraq, one of the most important SDS paths in West Asia (Zoljoodi et al., 2013), this area usually deposits sand particles to central and southwestern Iran. Sistan Basin, in addition to its significant impact on Sistan and Baluchistan province, is also an important source responsible for the dust storms in Pakistan and Afghanistan (Ekhtesasi and Gohari, 2013; Cao et al., 2014).

Al-Howizeh/Al-Azim marshes consist of two main types of SDS source areas (Area $a$ and Area $b$ in Fig. 4). The first type, Area a, is close to the Iraq-Iran border, which has long been dry and has developed sand dunes. The other type, Area b, is experiencing rapid land degradation or desertification. Without immediate intervention and protection, the SDS source area of Area $b$ will eventually turn into the first type, i.e. Area a, and cannot be restored. SDS source in Sistan Basin shows another characteristic which we can conclude from the obvious stripes in the image: strong wind erosion. Large quantities of sand particles would be uplifted by the intense "Levar" winds in summer and stretch to Iran, Afghanistan and Pakistan (Rashki et al., 2012; Ekhtesasi and Gohari, 2013).

\subsubsection{Al-Howizeh/Al-Azim marshes}

According to the HISD dataset, soil degradation is extremely severe in Al-Howizeh/Al-Azim marshes. Temperature is also higher in this region than in other provinces due to the desert climate here. Within the part of Al-Howizeh/ Al-Azim marshes in Khuzestan province, cities of Dezful, Ahvaz, Masjed-e-Soleiman, Abadan and Bostan have suffered more dust storms in recent decades (Zarasvandi et al., 2011). Marshes between Tigris and the Euphrates alluvial plain used to be the largest wetlands in southwest Asia. However, 


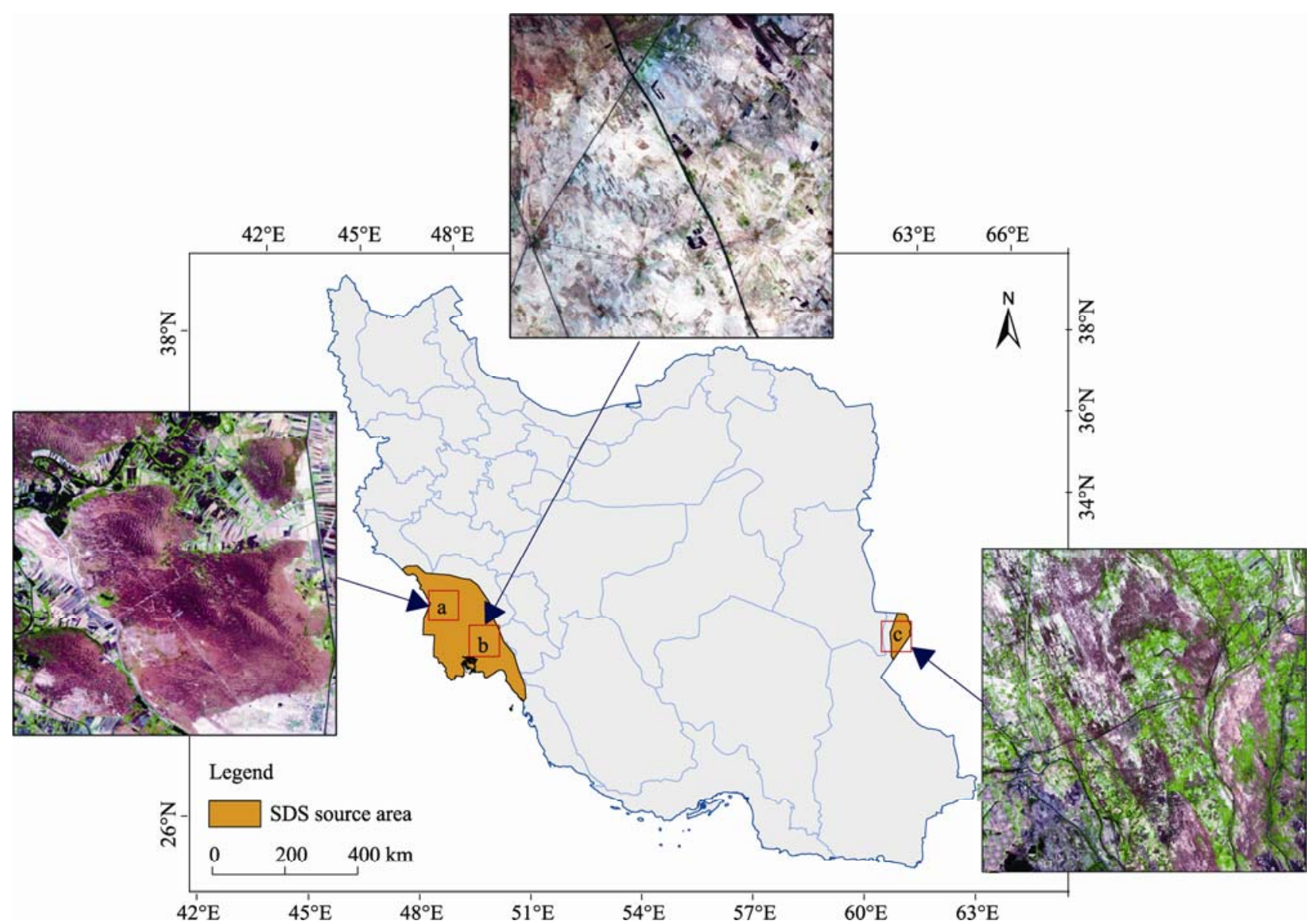

Fig. 4 SDS source areas in Iran and their characteristics on Landast 8 images. Area a is covered by sand dunes; Area b shows rapid land degradation; and Area c suffers strong wind erosion.

Al-Howizeh/Al-Azim marshes are now the only remaining marshes straddling the border of Iraq and Iran (Richardson and Hussain, 2006). To make matters worse, Al-Howizeh/Al-Azim marshes have also been suffering from an accelerating rate of deterioration within the last decades due to climate change, drought, military operations, over exploitation, dam projects, etc (Ali and Mahdi, 2008; Morabbi, 2011; Muhsin, 2011). It would be well understood that, at a high rate of degradation, Al-Howizeh/Al-Azim marshes are likely to totally vanish in the next few years (Ghadiri, 2006). Dust particles generated from this area also cause severe impacts on human health. For example, due to the chemical bombardment during the Iraq-Iran war (1980-1988), the soil became contaminated with heavy metals (Keramat et al., 2011), which could induce many diseases either by transportation of dust particles in air (Zarasvandi et al., 2011) or by sand deposition into water resources. Under the influence of frequent dust phenomena, the parameters of water quality including EC (electrical conductivity), TDS (total dissolved solids) and turbidity have exceeded beyond the standard levels in Karun River, the largest river in Iran. In any case, Al-Howizeh/Al-Azim marshes call for an immediate action to prevent land degradation and combat sand and dust storms.

\subsubsection{Sistan Basin}

Being affected by a series of factors including the complete dryness of Hamoun lakes, the reduction in soil moisture and vegetation cover, and the construction of reservoir dams and irrigation projects upstream (Rashki et al., 2013b; Alizadeh-Choobari et al., 2014), Sistan Basin has now become another significant SDS source in West Asia. Because of the intensity, duration, wind speed and altitude of dust storms in Sistan Basin, dust loading from this area might have an important influence on the development of extreme dust 
storms, especially in the summer (Rashki et al., 2012).

Wind erosion stripes are obvious in the Landsat 8 images of Sistan Basin, corresponding to the fact that this area suffers the most persistent strong near-surface winds lasting at least 4 months per year and occasionally reaching more than $28 \mathrm{~m} / \mathrm{s}$ (McMahon, 1906; Saboohi et al., 2012). Generally, the frontal winds in Sistan Basin can be categorized into two major classes, namely: ordinary front winds and hurricane front winds. Ordinary front winds usually have higher speeds but lower tensile strength, while hurricane front winds move upward and through the gap created in the front and crest of the storm drag with more dust upwards (Ekhtesasi and Gohari, 2013). As for dust materials, dust storms in this area mainly consist of large quantities of quartz-rich, feldspar and mica-bearing silt, as well as mafic components from flood basalt sources and carbonate minerals from dolomites (Rashki et al., 2013b).

\section{Conclusions}

By use of the existing datasets and their accessibility, we developed an average weight allocation approach to identify the SDS source areas in Iran. Each dataset was reproduced into uniform format for the convenience of overlay analysis, with series processes of reprojection, data format conversion, resampling, data normalization and interpolation. The score map was generated through the overlaying of each weighted dataset, and the final SDS source areas were identified correspondingly.

The score map for the possibility of SDS sources is generally in agreement with current situation and existing literatures, except for several large cities with significant human influence. Two main SDS source clusters located in Al-Howizeh/Al-Azim marshes and Sistan Basin were identified. Al-Howizeh/Al-Azim marshes are suffering rapid land degradation caused by natural and human-induced factors, and might vanish soon in the future. Without immediate action and protection, this area could generate more areas of SDS source. Sistan Basin always undergoes significant wind erosion and might contribute to extreme or super dust storms in summer.

In this paper, we developed an approach to identify SDS source areas in Iran using multiple datasets. The identification of SDS source areas will enable us to assess the socio-economic and environmental impacts of dust storms, and find effective strategies in controlling and combating SDS. Further research shall focus on the improvement of weight allocation criterion and the attempt for SDS source monitoring and forecasting.

\section{Acknowledgements}

This research was funded by the Small Scale Funding Agreement (UNEP/ROWA). The first author appreciates Dr. WANG Yongdong and Miss ZHOU $\mathrm{Na}$ from Xinjiang Institute of Ecology and Geography, Chinese Academy of Sciences for their great and valuable help in data collection.

\section{References}

Ali S M, Mahdi A S. 2008. Digital techniques for monitoring changes in water-body using satellite image. Iraqi Journal of Science, 49(1): 244-255.

Alizadeh-Choobari O, Zawar-Reza P, Sturman A. 2014. The "wind of 120 days" and dust storm activity over the Sistan Basin. Atmospheric Research, 143: 328-341.

Amiraslani F, Dragovich D. 2011. Combating desertification in Iran over the last 50 years: an overview of changing approaches. Journal of Environmental Management, 92(1): 1-13.

Ashrafi K, Motlagh M S, Aslemand A, et al. 2014. Dust storm simulation over Iran using HYSPLIT. Journal of Environmental Health Science and Engineering, 12: 9.

Azizi G, Shamsipour A, Miri M, et al. 2012. Statistic and synoptic analysis of dust phenomena in west of Iran. Journal of Environmental Studies, 38(3): 31-33.

Barnum B H, Winstead N S, Wesely J, et al. 2004. Forecasting dust storms using the CARMA-dust model and MM5 weather data. Environmental Modelling and Software, 19(2): 129-140.

Boloorani A D, Nabavi S O, Azizi R, et al. 2013. Characterization of Dust Storm Sources in Western Iran Using a Synthetic Approach. Advances in Meteorology, Climatology and Atmospheric Physics. Berlin Heidelberg: Springer, 415-420.

Bryant R G. 2013. Recent advances in our understanding of dust source emission processes. Progress in Physical Geography, 37(3): 397-421.

Bullard J E, Harrison S P, Baddock M C, et al. 2011. Preferential dust sources: a geomorphological classification designed for use in global dust-cycle models. Journal of Geophysical Research, F04034, doi: 10.1029/2011JF002061.

Cao H, Amiraslani F, Liu J, et al. 2014. Identification of dust storm source areas in West Asia using multiple environmental datasets. Science of the Total Environment, 502: 224-235.

Dadizadeh M, Malakooti H, Gheiby A, et al. 2013. Study of long-term trend in dust distribution over Persian Gulf: satellite Imagery application and weather charts interpretation. In: Proceedings of $7^{\text {th }}$ Symposium on Advances in Science and Technology. BandarAbbas, Iran. 
Draxler R R, Hess G D. 1997. Description of the HYSPLIT_4 modeling system. In: NOAA Technical Memorandum ERL ARL-224. Air Resources Laboratory. Silver Spring, Maryland, USA.

Ekhtesasi M R, Gohari Z. 2013. Determining area affected by dust storms in different wind speeds, using satellite images (case study: Sistan plain, Iran). Desert, 17(1): 193-202.

Esmaili O, Tajrishy M, Arasteh P D. 2006a. Evaluation of dust sources in Iran through remote sensing and synoptical analysis. In: Atlantic Europe Conference on Remote Imaging and Spectroscopy, United Kingdom. 136-143.

Esmaili O, Tajrishy M, Arasteh P D. 2006b. Results of the 50 year ground-based measurements in comparison with satellite remote sensing of two prominent dust emission sources located in Iran. In: Remote Sensing of Clouds and the Atmosphere XI. International Society for Optics and Photonics, doi: 10.1117/12.692989.

FAO. 2008a. Global Change in Rain-Use Efficiency 1981-2003. [2013-10-12]. http://www.fao.org/geonetwork/srv/en/main.home.

FAO. 2008b. Global NPP Loss In The Degrading Areas 1981-2003. [2013-10-12]. http://www.fao.org/geonetwork/srv/en/main.home.

Furman H K H. 2003. Dust storms in the Middle East: sources of origin and their temporal characteristics. Indoor and Built Environment, 12(6): 419-426.

Gerivani H, Lashkaripour G R, Ghafoori M, et al. 2011. The source of dust storm in Iran: a case study based on geological information and rainfall data. Carpathian Journal of Earth and Environmental Sciences, 6(1): 297-308.

Ghadiri H. 2006. Restoration of Mesopotamian Marshlands. In: $2^{\text {nd }}$ International Conference on Environmental Science and Technology (ICEST 2006). American Science Press.

Ginoux P, Chin M, Tegen I, et al. 2001. Sources and distributions of dust aerosols simulated with the GOCART model. Journal of Geophysical Research, 106(D17): 20255-20273.

Givehchi R, Arhami M, Tajrishy M. 2013. Contribution of the Middle Eastern dust source areas to PM10 levels in urban receptors: case study of Tehran, Iran. Atmospheric Environment, 75: 287-295.

Goudie A S, Middleton N J. 2006. Desert Dust in the Global System. Berlin: Springer-Verlag Berlin, Heidelberger.

Goudie A S. 2009. Dust storms: recent developments. Journal of Environmental Management, 90(1): 89-94.

Hamidi M, Kavianpour M R, Shao Y P. 2013. Synoptic analysis of dust storms in the Middle East. Asia-Pacific Journal of Atmospheric Sciences, 49(3): 279-286.

Higashi T, Kambayashi Y, Ohkura N, et al. 2014. Exacerbation of daily cough and allergic symptoms in adult patients with chronic cough by Asian dust: a hospital-based study in Kanazawa. Atmospheric Environment, 97: 537-543.

Illius A W, O'connor T G. 1999. On the relevance of nonequilibrium concepts to arid and semiarid grazing systems. Ecological Applications, 9(3): 798-813.

ISRIC (International Soil Reference and Information Centre). 1990. Global Assessment of Human-induced Soil Degradation (GLASOD). [2013-10-15]. http://www.isric.org.

ISRIC (International Soil Reference and Information Centre). 2013. SoilGrids1km. [2013-10-02]. http://www.soilgrids.org.
Keramat A, Marivani B, Samsami M. 2011. Climatic change, drought and dust crisis in Iran. World Academy of Science, Engineering and Technology, 6: 10-13.

Kousari M R, Ahani H, Hendi-zadeh R. 2013. Temporal and spatial trend detection of maximum air temperature in Iran during 1960-2005. Global and Planetary Change, 111: 97-110.

Li P, Jiang L G, Feng Z M. 2013. Cross-comparison of vegetation indices derived from Landsat-7 Enhanced Thematic Mapper Plus (ETM+) and Landsat- 8 Operational Land Imager (OLI) sensors. Remote Sensing, 6(1): 310-329.

McMahon H. 1906. Recent survey and exploration in Seistan. The Geographical Journal, 28(3): 209-228.

Modarres R, da Silva V P R. 2007. Rainfall trends in arid and semi-arid regions of Iran. Journal of Arid Environments, 70(2): 344-355.

Mohammad R. 2012. Using thermal infrared (TIR) data to characterize dust storms and their sources in the Middle East. Pittsburgh: University of Pittsburgh.

Mohammadi F, Kamali S, Eskandary M. 2014. Tracing dust sources in different atmosphere levels of Tehran using hybrid single-particle lagrangian integrated trajectory (HYSPLIT) model. Scientific Journal of Pure and Applied Sciences, 3(7): 559-571.

Morabbi M. 2011. Risk warning and crisis management for dust storm effects on western border of Iran. In: United Nations International Conference on Space-based Technologies for Disaster Risk Management. Beijing, China.

Muhs D R. 2013. The geologic records of dust in the Quaternary. Aeolian Research, 9: 3-48.

Muhsin I J. 2011. Al-hawizeh marsh monitoring method using remotely sensed images. Iraqi Journal of Science, 52(3): 381-387.

NOAA. 2013. Hourly/Sub-Hourly Observational Data. [2014-03-17]. http://gis.ncdc.noaa.gov.

Oldeman L R, Hakkeling R T A, Sombroek W G. 1990. World map of the status of human-induced soil degradation: an explanatory note. Wageningen and Nairobi: International Soil Reference and Information Centre.

Pegah Amiirdiivanii F H. 2012. I.R of Iran National Report on Regional Action Plan to combat dust and sand storm. In: International Cooperative for Aerosol Prediction (ICAP) $4^{\text {th }}$ Workshop: Aerosol Emission and Removal Processes. Frascati.

Powell J T, Chatziefthimiou A D, Banack S A, et al. 2015. Desert crust microorganisms, their environment, and human health. Journal of Arid Environments, 112: 127-133.

Prospero J M, Ginoux P, Torres O. 2002. Environmental characterization of global sources of atmospheric soil dust identified with the NIMBUS 7 Total Ozone Mapping Spectrometer (TOMS) absorbing aerosol product. Reviews of Geophysics, 40(1): 1-31.

Rahimi M, Yazdani M R, Asadi M, et al. 2014. Temporal and spatial variability of dust storm events in West Asia (Iran and Iraq border). International Journal of Civil and Environmental Research, 1(3): 100-109.

Rashki A, Kaskaoutis D G, Rautenbach C J W, et al. 2012. Dust storms and their horizontal dust loading in the Sistan region, Iran. Aeolian Research, 5: 51-62.

Rashki A, Kaskaoutis D G, Goudie A S, et al. 2013a. Dryness of ephemeral lakes and consequences for dust activity: the case of the 
Hamoun drainage basin, southeastern Iran. Science of the Total Environment, 463-464: 552-564.

Rashki A, Eriksson P G, Rautenbach C J W, et al. 2013b. Assessment of chemical and mineralogical characteristics of airborne dust in the Sistan region, Iran. Chemosphere, 90(2): 227-236.

Richardson C J, Hussain N A. 2006. Restoring the Garden of Eden: an ecological assessment of the marshes of Iraq. BioScience, 56(6): $477-489$.

Saboohi R, Soltani S, Khodagholi M. 2012. Trend analysis of temperature parameters in Iran. Theoretical and Applied Climatology, 109(3-4): 529-547.

Snyman H A. 1998. Dynamics and sustainable utilization of rangeland ecosystems in arid and semi-arid climates of southern Africa. Journal of Arid Environments, 39(4): 645-666.

UNEP, GRID-Europe. 2014. Droughts events 1980-2001. [2013-10-09]. http://www.preventionweb.net/english/maps.
Wang Y Q, Stein A F, Draxler R R, et al. 2011. Global sand and dust storms in 2008: observation and HYSPLIT model verification. Atmospheric Environment, 45(35): 6368-6381.

Wilderson W D. 1991. Dust and sand forecasting in Iraq and adjoining countries. In: Technical Report, Air Weather Service. Scott AFB (AWS/XTX), IL, USA.

WMO, UNEP. 2013. Establishing a WMO sand and dust storm warning advisory and assessment system regional node for West Asia: current capabilities and needs. In: WMO Technical Report, 1121.

Zarasvandi A, Carranza E J M, Moore F, et al. 2011. Spatio-temporal occurrences and mineralogical-geochemical characteristics of airborne dusts in Khuzestan Province (southwestern Iran). Journal of Geochemical Exploration, 111(3): 138-151.

Zoljoodi M, Didevarasl A, Saadatabadi A R. 2013. Dust events in the western parts of Iran and the relationship with drought expansion over the dust-source areas in Iraq and Syria. Atmospheric and Climate Sciences, 3: 321-336. 